\title{
Effect of Generator (Exhaust) Fumes on the Growth and Development of Lycopersicum esculentus (Tomato)
}

\author{
*1Chukwu, MN; Adams, EA. \\ Biology Unit, School of Science and Technology, National Open University of Nigeria, Lagos \\ E-mails: ${ }^{1}$ mchukwu@noun.edu.ng and emmanueladams1@yahoo.com ${ }^{2}$
}

\begin{abstract}
The effects of generator (Exhaust) Fumes on the growth and development of Lycopersicum esculentus were evaluated in this study. It involved sowing ten seeds of $L$. esculentus in plastic pots. These were allowed to germinate and stabilize for two weeks after which they were exposed to $0.75 \mathrm{KVA}$ generator fumes 8 hours a day at the distance of $3 \mathrm{~m}$, $6 \mathrm{~m}$, and $9 \mathrm{~m}$ respectively from the source while the control was retained at the planting site. Results were analyzed using analysis of variance (ANOVA) and Pearson's correlation coefficient at $5 \%$ level of significance. Although the mean dry weights of the plants increased as the distance of the plants from the source of pollution increased, only the $3 \mathrm{~m}$ treatment led to significant reduction of the growth rate of the seedlings $(p<0.05)$. The heights of the plants were adversely affected by the fume emission especially at the distance of $3 \mathrm{~m}$ away from the source $(\mathrm{p}<0.05)$. The leaf number per plant increased as the distance of the plants from the source of pollution increased with significant effects on plant from distance of $3 \mathrm{~m}$ and $6 \mathrm{~m}$ at the later stage of their growth $(\mathrm{p}<0.05)$. Significant differences $(\mathrm{p}<0.05)$ were observed among the plants in the different treatments for the different parameters measured. . Farmers should locate their farmlands at a distance of at least $50 \mathrm{~km}$ away from the factories to minimize effect of air pollutants and the government should also place a ban on importation of old generators. (C) JASEM
\end{abstract}

\section{http://dx.doi.org/10.4314/jasem.v20i2.14}

Key words: generator fume, emission, Lycopersicum esculentus, growth, germination

\section{Introduction}

The fundamental problem facing the electric power sector in Nigeria is inadequate power generation. This is to an extent due to the bridge of policies, inadequate infrastructure and economic challenges. Most Nigerians go without power supply for weeks and months as the case may be. This has hampered the nation's economic development in industrial and private sectors (Emeka, 2008). It has also been asserted that presently $60 \%$ to $70 \%$ of the Nigerian population does not have access to electricity (Ajanaku, 2007; Adegbamigbe, 2007 and Oyedeo 2012). Industrial and private sectors, business oriented minds and domestic homes thus source for alternative source of electricity through the use generators (Ajanaku, 2007).

The generators being put to constant use generate a lot of pollutants. Exhaust fumes produced by these generators contain many toxic substances such as hydrocarbons, fluorides, nitrates and oxides of carbon, nitrogen, sulphur, lead, carcinogenic benzo (a) pyrene and soot particles which are not only harmful to the atmosphere, but also to the ecosystems as a whole (Timbrell, 1991, Guadalupe, 2012, Rudell et al., 1999 and John et al, 2006). Fluorides damage the edges of plants' leaves turning them brown or black while Peroxyacyl nitrates cause the leaves to turn silvery white or bronze (Cynthia, 2010)

Carbon IV oxide brings about greenhouse effect while sulfur oxides and sulfates create acid rain. These change the colors of leaf and the overall structure of plants, reducing their growth rates and eventually killing them. Benzene on the other hand, causes cancer in animals and kills plants while soot particles impair breathing, damage lung tissue and cause cancer in animals (Cynthia, 2010).

Soot particles when deposited on plants' leaves block the stomata, hinder sunlight from penetrating into the leaves, reduce the amount of Carbon IV oxide that can be absorbed by the leaves and consequently reduce the rate of photosynthesis. These lead to reduced growth rate of plants and eventually death (John et al, 2006).

Vehicle emissions release nitrogen into the atmosphere. In near busy roads, some of the emissions fall to the ground, affecting the plants, (Jayaratne et al., 2010). Bignal et al., 2008 reported that leaves of 
plants do get clogged with a complex mixture of airborne pollutants emitted from motor vehicles. They found that bryophytes near highly used roads were more nitrogen-tolerant than those farther away from the road.

Plant growth can be defined as the increase of dry materials in plant or the increase of plant parts numerically while plant development refers to the changes during the life history of the plant (Odabas et $a l ., 2005)$. Determinants of plant growth include plant dry weight, height, leaf area and leaf number while growth analysis parameters include leaf area ratio (LAR), Net assimilation rate (NAR) and relative growth rate (RGR). Kathirvelan and Kalaiselvan (2007) reported that the leaf surface area determines in large part the amount of carbon gained through photosynthesis and the amount of water lost through transpiration and ultimately the crop yield.

The study was designed to investigatee the effect of exhaust fumes, especially from generators, on the growth and development of Lycopersicum esculentus.

\section{MATERIALS AND METHODS}

Sixteen plastic pots $(19.5 \mathrm{~cm}$ diameter and $20 \mathrm{~cm}$ depth) were each three - quarter filled with $5 \mathrm{~kg}$ of loam soil. Ten seeds of L. esculentus were sown into each plastic pot and watered every two days. They were allowed to germinate and stabilize. Two weeks after planting, they were divided into four groups of four replicates each. The groups of plants were then exposed to a $0.75 \mathrm{KVA}$ generator fumes at the distance of $3 \mathrm{~m}, 6 \mathrm{~m}$, and $9 \mathrm{~m}$ respectively from the source while the control is retained at the planting site. These were exposed to the fumes for 8 hours a day at the temperatures of $95^{\circ} \mathrm{C}, 80^{\circ} \mathrm{C}, 50^{\circ} \mathrm{C}$ and $30^{\circ} \mathrm{C}$ respectively.

Four plants from each treatment were randomly harvested for assessment every two weeks until twelve weeks after planting. At each harvest, their leaf areas were calculated using the formula: $0.5 \mathrm{LB}(\mathrm{L}=$ length and $\mathrm{B}=$ breadth) after measuring the length and the breadth of a leaf of each plant sample according to Pearcy et al. (1989). Their fresh weights were also measured with an Acculab Electronic scale. The samples were thereafter packed in paper bags and oven dried at $60^{\circ} \mathrm{C}$ in an oven (Memmert 854 Mchwabach model) for 24 hours and afterwards their dry weights taken (Merkl et al, 2004). Growth analysis parameters such as the leaf area ratio (LAR), net assimilation rate (NAR) and relative growth rate (RGR) were calculated for comparison.

Results were analyzed using analysis of variance (ANOVA). Further comparison of the treatments was carried out using Pearson's correlation coefficient at 0.05 probability level.

\section{RESULTS AND DISCUSSION}

Dry weight: The mean dry weights of $L$. esculentus at varying distance from the source were shown in Figure 1. The plants recorded their highest mean dry weights from the control and the least form plants kept $3 \mathrm{~m}$ away from the fumes' source at all harvest periods. The mean dry weights of $L$. esculentus plants from all the treatments increased as the experiment progressed with a significant difference between the dry weights of $L$. esculentus plants from the control and $L$. esculentus plants at $9 \mathrm{~m}$ from the source and those plants kept $3 \mathrm{~m}$ and $6 \mathrm{~m}$ away from the source respectively $(\mathrm{P}<0.05)$.

The lower mean dry weights from L. esculentus plants exposed to generator fumes indicated that the toxic substances in the fume reduced the growth rate of $L$. esculentus plants. The marked reduction in the dry weights of plants kept $3 \mathrm{~m}$ away from the fumes' source at all harvest periods showed that the effect was most severe in that treatment. This is in agreement with the findings of John et al, (2006) that soot from soot particles reduced the growth rate of plants.

Plant height: Mean plant height of $L$. esculentus increased as the experiment progressed from the first to the fifth harvest (Fig. 2). L. esculentus plants from the control were the tallest followed in decreasing order by those at $9 \mathrm{~m}$ and $6 \mathrm{~m}$ away from the source respectively. L. esculentus plants $3 \mathrm{~m}$ away from the source had significantly the lowest height $(\mathrm{P}<0.05)$. However, no significant mean plant height difference was found between L. esculentus plants from the control and those $9 \mathrm{~m}$ from the source. These results clearly indicated that the generator fumes inhibited plant growth as evidenced by increase in plant height the farther away the plants were from the source of pollution. The findings are in agreement with the findings of John et al, 2006 that toxic components from exhaust fumes produced by generators inhibit the growth of plants. 


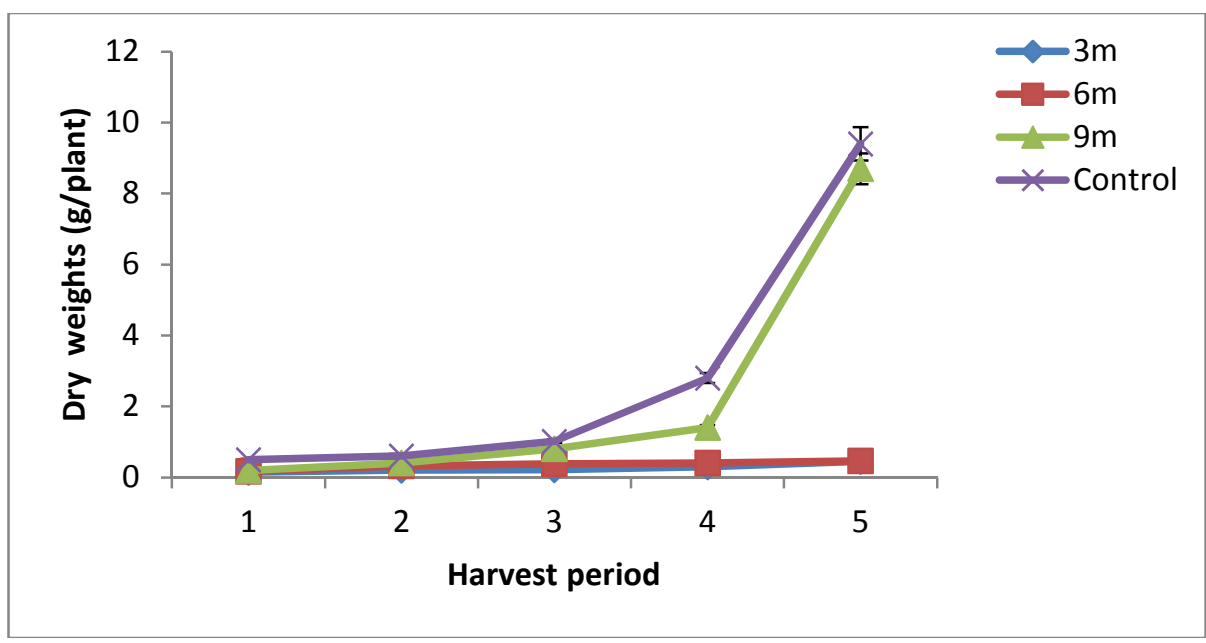

Fig. 1: Mean dry weights (g/ plant) of L. esculentus at varying distance from the source. Values shown are mean \pm SE.

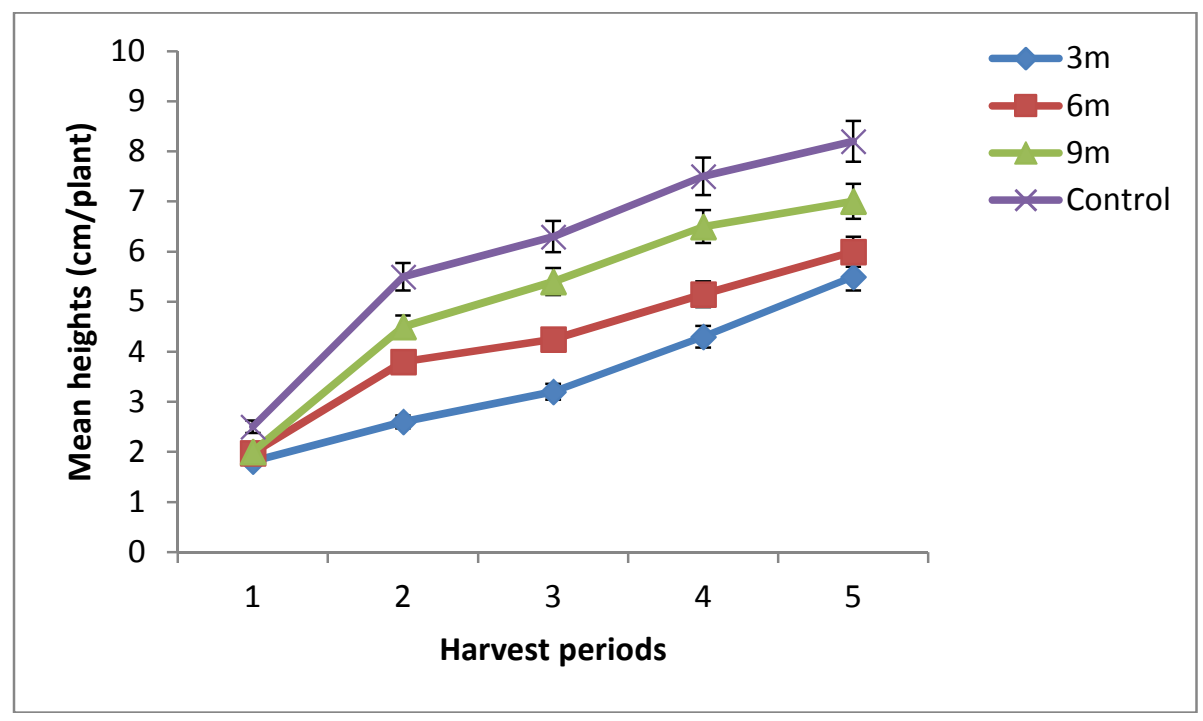

Fig. 2: Mean heights (cm/plant) of L. esculentus at varying distance from the source. Values shown are mean \pm SE.

Leaf Area (LA): The mean leaf area also increased with increasing distance from the source (Figure 3). There was also a progressive increase in the LA of $L$. esculentus plants from all the treatments as the experiment progressed. L. esculentus plants at $3 \mathrm{~m}$ from the source recorded the least LA and those from the control the highest at all harvest periods. The decrease in leaf area of $L$. esculentus plants in this study due to generator fume pollution indicated that the fume interrupted the growth of the L. esculentus plants. This implied that there would be low photosynthetic efficiency leading to low yield of the $L$. esculentus plants and consequently poor economy due to low sales of such products. The leaf area of the plants significantly differed from those of the control and also those of plants $3 \mathrm{~m}$ from the source $(\mathrm{p}<0.5)$. These findings are in congruent with those of Kathirvelan and Kalaiselvan (2007) who reported that leaf surface area determines largely the amount of carbon gained through photosynthesis and the amount of water lost through transpiration and consequently the crop yield. 


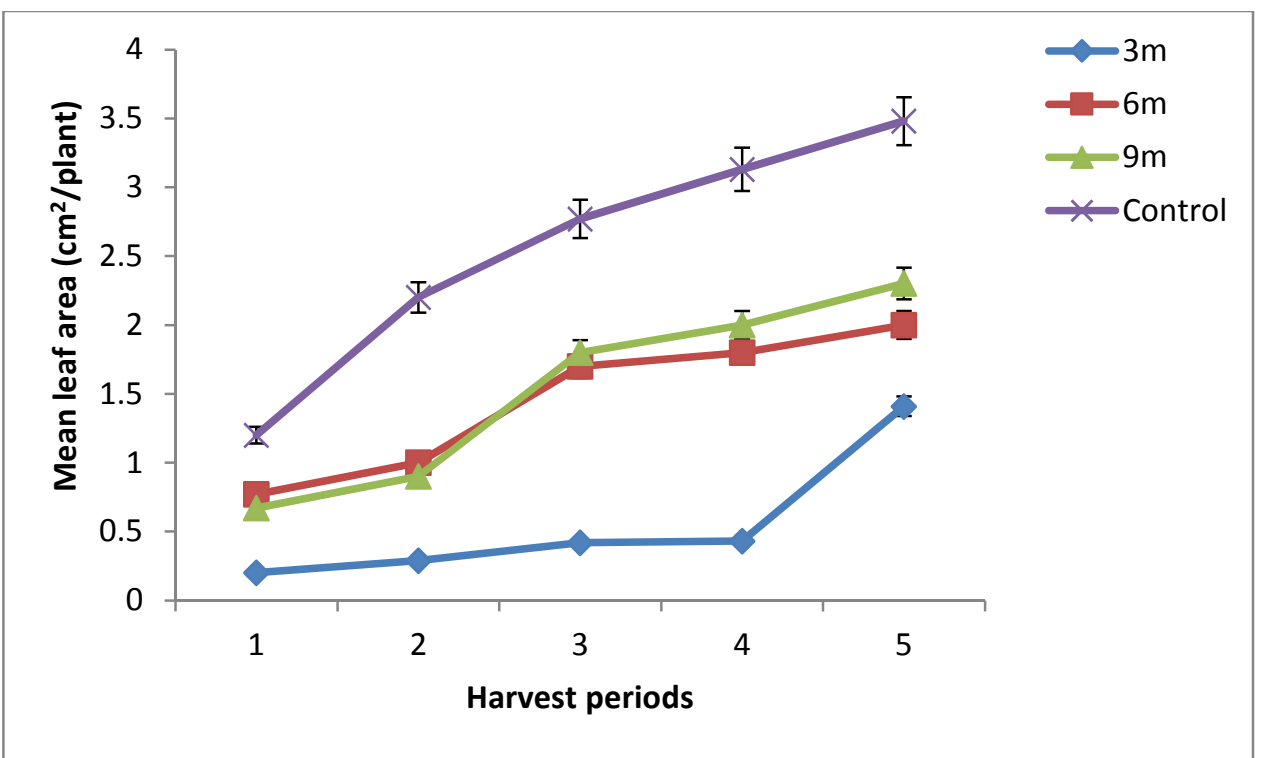

Fig. 3: Mean leaf areas $\left(\mathrm{cm}^{2} /\right.$ plant) of L. esculentus at varying distance from the source. Values shown are mean \pm SE.

Leaf number per plant: Plants of L. esculentus had similar mean number of leaves at the start of the experiment. However, as the experiment progressed; between the third and the fifth harvest, L. esculentus plants from the control were observed to be the highest developer of new leaves and those of plants $3 \mathrm{~m}$ from the source the least (Figure 4). Like other growth parameters assessed, development of new leaves was slowest with a significant marked reduction in $L$. esculentus plants $3 \mathrm{~m}$ from the source $(\mathrm{P}<0.05)$. This indicated that relatively, emitted fumes from the generator reduced the growth and development of new leaves in the treatment.

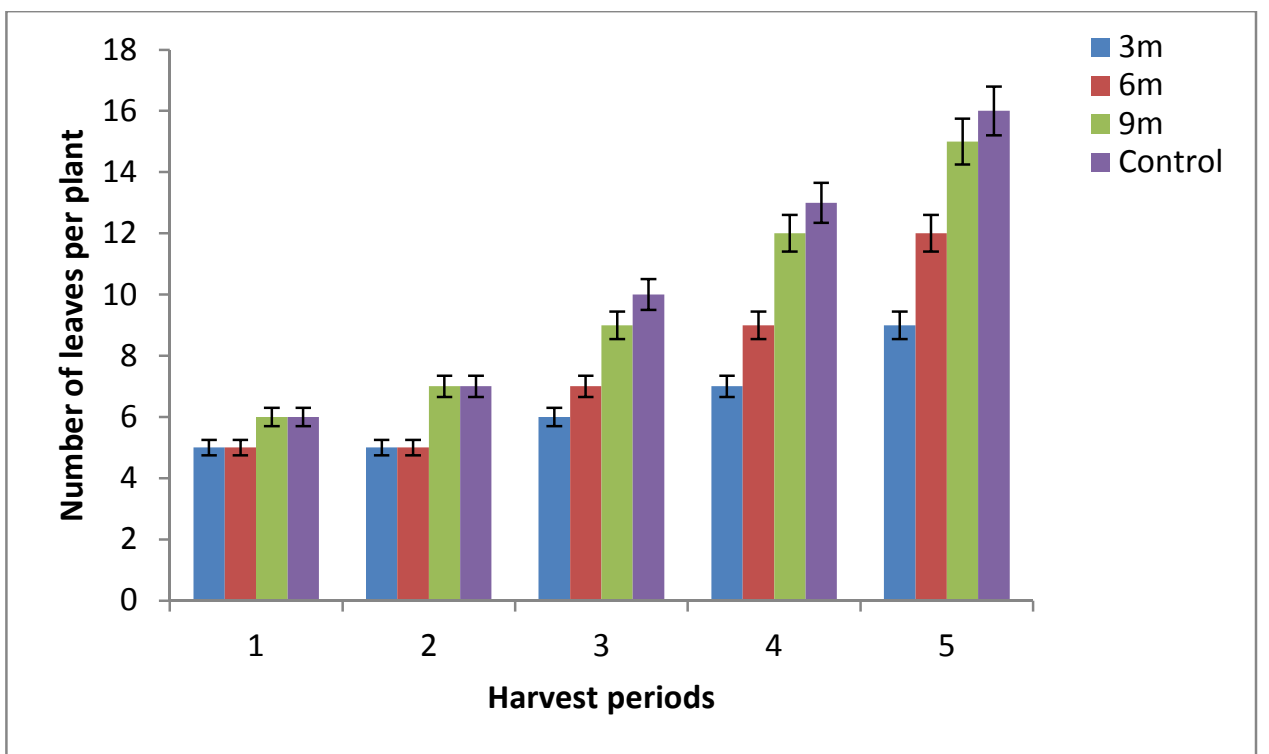

Fig. 4: Number of leaves per plant of L. esculentus at varying distance from the source. Values shown are mean \pm SE.

Leaf Area Ratio (LAR): The data for the LAR of $L$. esculentus plants at varying distance from the source were summarized in Table 1. Results showed that plants of L. esculentus experienced a gradual decrease in LAR values from the first to the last sampling interval in all treatments except those of plants $3 \mathrm{~m}$ away from the source which showed a fluctuation in their LAR values through sampling intervals. There is 
no significant difference in the LAR values of all the treatments $(\mathrm{P}<0.05)$.

Table 1: Mean leaf area ratio $\left(\mathrm{cm}^{2} / \mathrm{g}\right)$ of $L$. esculentus plants at varying distance from the source

\begin{tabular}{lcccc}
\hline Sampling intervals & Control & $\mathbf{3 ~ m}$ & $\mathbf{6 ~ m}$ & $\mathbf{9 ~ m}$ \\
\hline First & $3.03 \pm 0.036$ & $1.39 \pm 0.260$ & $3.83 \pm 0.250$ & $2.89 \pm 0.251$ \\
Second & $3.00 \pm 0.220$ & $1.68 \pm 0.153$ & $3.80 \pm 0.178$ & $2.25 \pm 0.420$ \\
Third & $1.72 \pm 0.240$ & $1.67 \pm 0.147$ & $3.21 \pm 0.380$ & $1.84 \pm 0.264$ \\
Forth & $0.75 \pm 0.345$ & $2.25 \pm 0.420$ & $3.21 \pm 0.144$ & $0.85 \pm 0.230$ \\
\hline
\end{tabular}

Net Assimilation Rate (NAR): Table 2 shows the NAR of $L$. esculentus at varying distance from the source. Plants of L. esculentus at $9 \mathrm{~m}$ from the source and those of the control experienced a gradual increase in their NAR values as the experiment progressed. On the other hand, plants $3 \mathrm{~m}$ and $6 \mathrm{~m}$ away from the source respectively showed fluctuations in their NAR values through sampling intervals. These fluctuations in NAR values the closer the plants are to the source of pollution is probably as a result of the influence of the fumes on the plants. There is no significant difference in the LAR values of all the treatments $(\mathrm{P}<0.05)$.

Table 2: Mean net assimilation rate $\left(\mathrm{g} / \mathrm{cm}^{2} / \mathrm{wk}\right)$ of L. esculentus plants at varying

\begin{tabular}{lcccc}
\multicolumn{5}{c}{ distance from the source } \\
\hline Sampling intervals & Control & $\mathbf{3 ~ m ~}$ & $\mathbf{6 ~ m}$ & $\mathbf{9 ~ m ~}$ \\
& & & & \\
\hline First & $0.03 \pm 0.000$ & $1.03 \pm 0.140$ & $0.09 \pm 0.002$ & $0.13 \pm 0.004$ \\
Second & $0.12 \pm 0.008$ & $0.21 \pm 0.012$ & $0.02 \pm 0.017$ & $0.15 \pm 0.001$ \\
Third & $0.30 \pm 0.010$ & $0.09 \pm 0.017$ & $0.35 \pm 0.026$ & $0.16 \pm 0.020$ \\
Forth & $0.99 \pm 0.012$ & $0.10 \pm 0.035$ & $0.02 \pm 0.034$ & $1.70 \pm 0.036$ \\
\hline
\end{tabular}

Relative Growth Rate (RGR): Table 3 shows the RGR of L. esculentus plants at varying distance from the source. There was also a progressive increase in the RGR of L. esculentus plants as the experiment progressed for all the treatments. Ecologically, high RGR depicts increased growth rate. There is however significant differences in the RGR values of plants from the control and those from $9 \mathrm{~m}$ treatment between sampling intervals $(\mathrm{P}<0.05)$.
Although there was variation in LAR, no clear correlation was found between LAR and RGR. The correlation between NAR and RGR on the other hand was extremely tight, thus, the more a plant invests in leaf area, the higher the total carbon gain and the faster growth will be.

Table 3: Mean relative growth rate (g/wk) of L. esculentus plants at varying distance from the source

\begin{tabular}{lcccc}
\hline Sampling intervals & Control & $\mathbf{3 ~ m}$ & $\mathbf{6 ~ m}$ & $\mathbf{9 ~ m}$ \\
& & & & \\
\hline First & $0.09 \pm 0.041$ & $0.05 \pm 0.030$ & $0.04 \pm 0.024$ & $0.06 \pm 0.007$ \\
Second & $0.27 \pm 0.033$ & $0.14 \pm 0.024$ & $0.05 \pm 0.028$ & $0.25 \pm 0.157$ \\
Third & $0.42 \pm 0.150$ & $0.15 \pm 0.016$ & $0.21 \pm 0.340$ & $0.37 \pm 0.183$ \\
Forth & $0.61 \pm 0.225$ & $0.21 \pm 0.022$ & $0.31 \pm 0.260$ & $0.52 \pm 0.202$ \\
\hline
\end{tabular}

Conclusion: The findings of this study showed that generator fumes adversely affect man and other living organisms in an ecosystem being deleterious to $L$. esculentus growth. The farther away the plants are from the source of the fume the less severe their effect. There is need to enlighten the public on the dangers associated with generator use in Nigeria. Farmers should locate their farmlands at a distance of at least $50 \mathrm{~km}$ away from the factories to minimize effect of air pollutants. The government should place a ban on importation of old generators, stating tail pipe emission standards, which is vital to successfully reducing pollutants emitted by generators.

\section{REFERENCES}

Adegbamigbe, A. (2007). Obasanjo's legacies. News, $28(21)$.

Ajanaku, L. (2007). Battling with Darkness. TELL (Special Edition). May 21, pp: 31-33. 
Bignal, K.L., M.R. Ashmore, \& A.D. Headley. (2008). "Effects of air pollution from road transport on growth and physiology of six transplanted bryophyte species". Environmental Pollution. 156: 332-340.

Cynthia Myers (2010): The Effect of Air Pollution on Plants. www google.com

Emeka, E.O. (2008). Development crisis of power supply and implications for industrial sector in Nigeria. Stud. Tribes Tribals, 6(2): 83-92.

Guadalupe M. (2012). Effect of Exhaust Fumes on plants. California state Science Fairs. S1722.

John W., Wargo L., Alderman N. and Brown D. (2006). The Harmful Effects of Vehicle Exhaust. A case for Policy change. Environment and Human Health. Inc

Kathirvelan P, Kalaiselvan P (2007). Groundnut (Arachis hypogaea L.) Leaf Area Estimation Using Allometric Model. Res. J. Agric. Biol. Sci., 3(1): 59-61

Merkl N, Schultze-Kraft R, Infante C. (2004). Phytoremediation in the Tropics. The Effect of
Crude Oil on the Growth of Tropical Plants. Bioremediation J. 8: 177-184.

Odabas M. S, Radusiene J., Camas. N., Janulis, V., Ivanauskas, L., Cirak, C. (2009). The Quantitative Effects of Temperature and Light Intensity on Hyper forin and Hypericins

Accumulation in Hypericum perforatum L. J. Med Plants Res 3(7): 519-525.

Pearcy, R. W., Ehleringer, J. R., Mooney, H., Rundel, P. W. (1989). Plant physiological ecology:

Field methods and instrumentation. Chapman and Hall, New York. pp. 301-306.

Rudell, B., U. Wass, P. Hörstedt, J. O. Levin, R. Lindahl, U. Rannug, A. L. Sunesson, Y.

Östberg, and R. Sanström. (1999). "Efficiency of automotive cabin air filters to reduce acute health effects of diesel exhaust in human subjects". Occupational and Environmental Medicine. 56(4): 222-231.

Timbrell, J.A. (1991). Principles of Biochemical Toxicology. 2nd Edition., Taylor and Francis

London, Washington, DC 